\title{
Advancing E-Roaming in Europe: Towards a Single "Language" for the European Charging Infrastructure ${ }^{\dagger}$
}

\author{
Roland Ferwerda ${ }^{1, *}$, Michel Bayings ${ }^{2}$, Mart van der Kam ${ }^{3}\left(\mathbb{D}\right.$ and Rudi Bekkers ${ }^{3(D)}$ \\ 1 NKL-The Netherlands Knowledge Platform for Public Charging Infrastructure, Vondellaan, \\ 1623521 GH Utrecht, The Netherlands \\ 2 eMobility Consulting, Vekenoord, 414824 LN Breda, The Netherlands; \\ michel.bayings@emobilityconsulting.com \\ 3 School of Innovation Sciences, Eindhoven University of Technology, PO Box 513, 5600 MB Eindhoven, \\ The Netherlands; m.j.kam@tue.nl (M.v.d.K.); r.n.a.bekkers@tue.nl (R.B.) \\ * Correspondence: rferwerda@nklnederland.nl; Tel.: +31-30-281-96-75 \\ + A Preliminary Version of This Article Was Presented at the EVS30 Symposium, Stuttgart, Germany, 9-11 \\ October 2017.
}

Received: 13 May 2018; Accepted: 5 December 2018; Published: 7 December 2018

\begin{abstract}
The E.U. market for electric vehicles (EVs) is growing significantly, but the absence of widely adopted protocols and interoperability standards for charging hinders the development of cross-border EV travel ("e-roaming"). In this paper, we present our vision on what should be the basic functionalities of e-roaming. Furthermore, we describe the best practices of 6 years of e-roaming in the Netherlands, and analyze what can be learned from other sectors that were successful in introducing roaming mechanisms in the past. We translate these into proposed next steps, such as the need for piloting e-roaming on a European level using open standards, such as Open Charge Point Interface (OCPI). We conclude with a proposal for a comparative study of protocols to pave the way for future convergence, and, thus, facilitate a European market for EV products and services.
\end{abstract}

Keywords: electric vehicle charging; roaming protocol; peer-to-peer; harmonization

\section{Introduction}

In recent years, the E.U. market for electric vehicles (EVs) has grown dramatically [1]. EVs are seen as one of the main technologies contributing to sustainable transport systems because of their potential for de-carbonization, improving air quality, and contributing to grid resilience $[2,3]$. The increase of EVs has been supported by the introduction and development of a charging infrastructure. However, the absence of accompanying E.U.-wide protocols and standards for interoperability and e-roaming (e.g., the option for EV drivers to charge their vehicles at all non-private charging stations) has severely hindered the development of cross-border EV travel within the E.U. [4,5]. Solutions for interoperability have had a national scope at best, which has primarily been caused by a lack of a single (open) standard for communication between the market parties involved. This has been recognized as a serious obstacle for further uptake of electric mobility in Europe $[5,6]$. A study by the market research firm Navigant Research [6] shows that, besides range (anxiety), the main obstacles for the acceptance of electric mobility by consumers are:

- Poor information about the location and availability of charging stations;

- An absence of information about tariffs and the total price of the session;

- Different, non-compatible ways, tools, tokens, and apps to obtain access to charging stations; and

- Non-transparent business models and a potentially high cost because of the complexity of the value chain. 
These obstacles can be tackled through standardization and interoperability of the charging infrastructure, and specifically the communication protocols that are responsible for information exchange between the back offices of involved stakeholders (e.g., charge point operators, mobility service providers, navigation service providers). With standardization and interoperability of the charging infrastructure, e-roaming becomes feasible. This will make transnational EV travel more comfortable, increase the adoption of e-mobility by consumers, and is a pre-condition for more advanced solutions in order to develop future mobility as a service and innovative e-mobility service concepts.

The purpose of this paper is to present our vision on the future of e-roaming. We expand upon the existing literature by describing the best practices of roaming in e-mobility and other sectors, and make specific proposals for future research. In particular, we describe how the Open Charge Point Interface (OCPI) protocol is a suitable candidate for being widely adopted as the standard for e-roaming in the E.U. In contrast to most other proposed protocols, it enables all different business models: bilateral roaming contracts as well as roaming hubs. The ambition to further develop it in an open standardization process makes this an attractive protocol from a European political/regulatory perspective as well. The rest of this paper is organized as follows. Section 2 discuss historical efforts to achieve harmonization of standards and interoperability. We discuss the standardization process, open standards, and E.U. policy on standards. We then contrast the current fragmentation in EV charging infrastructure with successful efforts to achieve interoperability in the telecommunications and Internet sectors and translate our findings to lessons learned for the e-mobility sector. Section 3 gives a brief overview of the current $\mathrm{EV}$ ecosystem and charging infrastructure and presents our vision on and rationale for e-roaming. We then point to ways forward by giving an overview of best practices in Section 4. Section 5 concludes the paper and contains a proposal for next steps.

\section{Harmonization by the Use of Standards}

\subsection{Standardization, Interoperability, and Harmonization}

A communication protocol for e-roaming can be classified as a compatibility standard, defined by Krechmer [7] as a standard that "defines the interface between two or more mating elements that are compatible rather than similar". Compatibility standards ensure interoperability between different systems, and are of particular importance in sectors such as telecom and information and communication technologies (ICT) [8,9]. One of the key economic incentives for the development of compatibility formats are network externalities [9], i.e., an increase in a network is accompanied by an increase of the value of that network. Compatibility standards can play a role in creating new services, since they define operating characteristics that are needed to develop new technologies [9]. Sometimes, compatibility standards even create entire new markets, such as in the case of the Global System for Mobile communications (GSM)/3G/4G standards for mobile telecommunications, and the Transmission Control Protocol/Internet Protocol (TCP/IP) standard for the Internet. A negative effect of compatibility standards can be that they create a monopoly [10]. Alternatively, gateway technologies can be used to achieve interoperability between different technologies and standards, though gateway technologies may not have the same economic benefits as compatibility standards and may come with extra costs and limited functionality [8]. Gateway technologies are attractive ex post, when no single standard has emerged from the standardization process.

Standards are not just neutral solutions, and the superior technology does not automatically become the standard $[8,11,12]$. Based on an extensive literature review, Van de Kaa et al. [13] have identified 29 success factors for winning interface format battles in market-based standard battles ("interface format" is used as an alternative term for "compatibility standard", the definitions of these concepts are very close in meaning). These factors are not only related to the technical specifications of an interface format, but also to the characteristics of the format supporter, the format support strategy, other stakeholders, and market characteristics. In formal standard setting processes, firms that are 
members of standard development organizations (SDOs) can engage in strategic behavior [9,14-16]. It can be financially attractive for a firm if it has a patented technology becoming part of a standard [17]. The issue of patented technologies in standards also relates to the discussion of open standards. The discussion on the 'openness' of standards became more prominent with the rise of personal computers and the Internet [7]. In response to this discussion, the World Trade Organization's Committee on Technical Barriers to Trade (WTO TBT) formulated the following six conditions for international standardization processes: (1) Transparency (regarding documentation on a proposal for standards and final standards), (2) openness (open membership at every stage of the standardization process), (3) impartiality and consensus (no privilege or favoring interests of a particular party), (4) effectiveness and relevance (facilitating international trade), (5) coherence (no duplication of or overlapping with the work of other standardization bodies), and (6) address the concerns of developing countries (developing countries should not be excluded de facto from the process) [18]. Also, in Europe, where the European Union has emphasized standards and interoperability as 'Pillar II' of its Digital Agenda for Europe, open standards are seen as the basis for future developments and play an important role in regulation and policy-making [19].

When a certain standard is considered a public good, governmental regulation may play an important part in the standardization process $[8,20]$. Societal benefits of standards include quality control, interoperability, safety, and positive effects on health and environment. Complying with a standard is usually voluntary, the exception being standards that are required by legislation. The E.U. has implemented a policy called the "New Approach". It states that adopting European standards (ENs) is voluntary, but E.U. legislation requires that products and services meet essential requirements. Any product that conforms to ENs is automatically assumed to meet these regulatory essential requirements. A party whose choses to offer products or services not based on these standards, can still do so, but has to prove itself that these products or services meet the regulatory essential requirements, which might require considerable effort. When a need for a standard is identified based on a specific directive, the European Commission (EC) requests one of the recognized European standardization organizations to develop the relevant standard. There are three recognized ("formal") European standardization organizations (ESOs): the European Committee for Standardisation (CEN), European Committee for Electrotechnical Standardisation (CENELEC), and the European Telecommunication Standards Institute (ETSI). These ESOs cooperate with national SDOs to ensure the alignment of European and national standards following Directive 98/34/EC [21]. The resulting standards are termed "harmonized standards", and, aside from the benefits of the standards named earlier, are aimed at strengthening European integration in the Single Market and increasing the global competitiveness of the E.U.

\subsection{Fragmentation: The Current EV Charging Infrastructure}

The European Union wants to stimulate the electrification of transportation, as it contributes to the goals of $\mathrm{CO}_{2}$ reduction set in the Paris agreement [22]. However, there are no European-wide regulations on charging infrastructure; the regulation is implemented at the national and local levels. The lack of central E.U. coordination may have been a factor in the fragmentation of charging infrastructure in Europe [23-25].

One example of this is the variety of plugs used to charge EVs. The first efforts to standardize the plugs needed for charging date from the period of the first introduction of EVs, around the turn of the 20th century [26]. However, at that time, the internal combustion engine (ICE) won the battle for market dominance, and EVs became a niche technology. Since the 1970s, due to concerns about oil-crises, resource depletion, climate change, and air pollution, EVs have slowly but surely re-emerged as a serious alternative to ICE vehicles. Many of the first projects of building up a public charging infrastructure were very localized, with little exchange of knowledge internationally [25]. The first explorative activities regarding standardizing EV plugs started in 1998 by CENELEC [27]. A next, important step was the publication of the IEC 62196-2 standard on EV plugs by the International 
Electrotechnical Commission (IEC) in 2011. This standard specifies not one but three different types of plugs for Alternating Current (AC) charging:

- Type 1, originally developed by SAE International and original equipment manufacturer Yazaki, and also known as SAE J1772;

- Type 2, originally developed by the electric equipment manufacturer Mennekes; and

- Type 3, originally developed by the EV plug Alliance.

The IEC, thus, chose to base the standard on the plugs already in use throughout the world, instead of specifying one worldwide standard. In fact, Type 1 was already common in North America and Japan, Type 2 in Germany, U.K., Sweden, Spain, Netherlands, and China, and Type 3 in Italy and France. Unrelated to the IEC standard, Tesla has developed its own plug for AC charging, which is used exclusively in Tesla vehicles in North America [23].

In addition to the AC charging plugs mentioned above, there are several standards for Direct Current (DC) charging:

- $\quad$ CHAdeMO, developed by a Japanese industry association bearing the same name, is mostly used in Japan and Europe, and also generally referred to as "Type 4";

- Combined Charging System (CCS) Combo 1, a Type 1 plug with added plugs for DC charging, now also standardized by the IEC and mostly used in North America;

- Combined Charging System (CCS) Combo 2, a Type 2 plug with added plugs for DC charging, now also standardized by the IEC and mostly used in Europe; and

- The Supercharger, for Tesla vehicles, a proprietary plug (not standardized) mostly used in North America as well as Europe [23].

Aside from these standards, many EVs can also be plugged-in through regular household electricity sockets using a special charge adapter. This way, charging is much slower (up to $15 \mathrm{~h}$ for a full charge) because of the limited power that such sockets can offer. This solution is mostly used by EV drivers that charge at home but have no dedicated charge station at home, or incidental charging at other locations, such as the homes of relatives or friends. It is not adopted as a solution for public charging infrastructure [27].

In an effort to reduce the variety in plugs, the EC introduced legislation making IEC Type 2 the standard for AC charging points in 2014, and the CCS Combo 2 was specified as a minimum standard for equipment of DC charging points [4]. While this would theoretically lead to one plug for each charging type, there exists already an installed base in Europe of charging points with either Type 3 or Type 4 plugs. Many DC charging points are equipped with both Type 4 and CCS Combo 2, and there have been attempts to offer both Type 2 and Type 3 connections in AC charging stations [23]. However, these multiple connections are not available everywhere, and EV drivers will continue to have to bring multiple cables/adapters to be able to connect at any charge point (at the risk that a charging point does not support any of these adapters). Meanwhile, Tesla continues to build and operate its own line of fast chargers.

Wiegmann et al. [27] studied why, at the early stage, no single standard for AC charging emerged in the E.U. market, and why, at a later stage, Type 2 was formally adopted as the single standard for AC charging. Having one type of plug has clear advantages for all parties involved in the EV ecosystem, since having access to a large charging infrastructure significantly increases the attractiveness of EVs. Wiegmann et al. finds that the main reason for fragmentation was that different parties had already invested in different solutions before there was a real effort to come to a European-wide standard. Some European countries, such as France, the Netherlands, and Germany, had explicit policy targets regarding the build-up of charging infrastructure, and were, therefore, not willing to wait for a common standard to emerge. In contrast, countries that did not have such an explicit goal were more hesitant with building charging infrastructure before a single standard had been defined.

In 2010, the EC requested CEN/CENELEC to establish a standard that includes only one EV plug, with a deadline in summer 2013. In January 2013, the EC cut the standardization process short and 
declared the Type 2 plug to be the common standard (the European Parliament and the E.U. Council still had to agree, and the official legislation was passed in 2014). For the EC to cut the standardization process short is exceptional, and the main reason for this decision is that it was believed to contribute to the E.U.'s competitive advantage as a first mover in e-mobility [27]. Other reasons may have been that the Type 2 connector was already considered the front-runner anyway, and a lack of belief that a consensus could be reached within CEN/CENELEC. Wiegmann et al. [27] found the following factors to contribute to the choice for Type 2 instead of Type 3 (note that Type 1 was not used a lot in Europe in the first place so not a real contender):

- $\quad$ Type 2 had a larger installed based than Type 3;

- $\quad$ Type 2 had support from strong alliances among car manufacturers;

- $\quad$ Type 2 was technologically superior;

- Mennekes, the developer of the Type 2 plug, declared it would license all related patents free of charge;

- China had adopted a variant of the Type 2 connector as its standard; and

- $\quad$ The U.S. automotive industry also supported Type 2.

Despite all these advantages, the IEC 62196-2 included three plugs, and not just Type 2. One factor was that Type 3 connectors include a shutter, conforming to French electric safety legislation [25,27]. Type 2 connectors did not have such a shutter. Mennekes argued that such a feature was unnecessary because of other safeguarding mechanisms built into the standards, and that such a shutter would instead reduce reliability because it could break off. Wiegmann et al. [27] speculate that emphasizing the importance of a shutter for safety may have been a strategic decision, since it would delay the decision on the standard. The time of the delay could have been used for stronger alliance building. If this was the case, that strategy backfired, since the delay triggered the EC intervention discussed above.

Next to charging plugs, there is also a lack of interoperability of payment systems [23]. Charging points can have different payment mechanisms, including cash, debit or credit cards, mobile phone apps, and SMS payments. Increasingly, however, charging operators use subscription models, where users identify themselves with Radio-Frequency Identification (RFID) cards. However, it is often not possible for these subscribers to use charging points from other operators. As a result, customers have to take multiple subscriptions at the same time. If they want to make a long, cross-border trip in Europe, they may need as much as a dozen subscriptions. As a response to this situation, the Directive 2014/94/EU on the deployment of alternative fuels infrastructure (AFID) [4] stated that charging point operators should offer charging services on an ad hoc basis. Furthermore, it stipulates that costumers under contract of one charge point operator (i.e., having a subscription) should be allowed to charge at any other operator. This requires roaming between the operators, which implies at least the following: (a) a contractual agreement between the operators, either direct (bilateral) or indirect (via a roaming hub or clearing house), (b) the charging point to be equipped with an internet connection, (c) an RFID card reader or a function for remote activation, and (d) interoperable communication protocols [23]. Both bilateral and hub initiatives have emerged in the E.U. [23,28]. However, there is no widely adopted, single standard communication protocol, and the ones that do exist have different focusses and are not all interoperable. We discuss e-roaming in greater detail in Sections 3 and 4.

\subsection{Harmonization: Roaming in Telecommunications and the Internet Protocol}

E-roaming is not the first market in which a need has arisen for a roaming infrastructure, and for an underlying, broadly adopted standard. We therefore investigated two earlier cases where significant efforts for harmonization and interoperability have taken place in order to identify lessons learned from these cases relevant to achieving harmonization in e-mobility. These cases we selected are (1) roaming in mobile telecommunications, in conjunction with the GSM, 3G, and 4G standards, and (2) roaming in the Internet, in conjunction with the Transmission Control Protocol/Internet Protocol 
(TCP/IP) suite. (Note that in the Internet case, people usually do not use the term "roaming"; however, the achieved functionality is very similar and, therefore, useful for our purpose.)

\subsubsection{Roaming in Mobile Telecommunications}

Roaming in mobile telecommunications allows a mobile user to connect to another mobile network, different from their "home" network, using their own Subscriber Identity Module (SIM)-card and phone number, without the need for an additional contract (subscription) [29]. The other network is typically a foreign network (international roaming), but can also be a network in the same country (national roaming). Such roaming services do not only require telecommunications facilities in order to realize calls and other services on the visited network, but also legal contracts, and an infrastructure for billing. To make the billing infrastructure possible, the home operator and the visited network operator either have a bilateral relation ("direct"), or use the services of a clearing house ("indirect"). Roaming services include voice calls, SMS, and mobile internet. The roaming agreement between the two operators specifies financial and legal matters, but also the data exchange format. Details of the data exchange are recorded in a Transferred Account Procedure (TAP) file for billing purposes. TAP files are exchanged between the two operators (direct roaming) or sent to a clearing house, which forwards them to the home operator (indirect roaming). Based on their wholesale roaming agreement, the home operator pays the visited operator.

Whereas some first-generation, analogue mobile networks in Europe already offered some (very limited) roaming services, the broad introduction of roaming took place along with the GSM standard, which was commercially introduced in 1991. In a setting where the European Union aimed to introduce a harmonized standard for the whole of Europe, in contrast to the then-existing, fragmented market of incompatible national technologies, the idea of cross-border, pan-European services played a central role. While the GSM standard itself offered the necessary technology for handling roaming calls-with a sophisticated set of technologies, such as Home Locations Registers (HLRs), Visitor Location Registers (VLRs), and authentication triplets-the necessary protocols for billing and accounting in the context of roaming were not part of the GSM standard as such. An association of operators, known as the GSM Association (GSMA), developed these protocols and associated agreements, such as Transferred Accounts Procedure (TAP), which is the protocol in use between virtually any roaming operator and roaming hub in the world.

Not long after the introduction of GSM, the roaming market faced a considerable challenge, when pre-paid services became a widespread phenomenon. Whereas regular, post-paid subscribers that roam can be charged afterwards by their home operator for the services they used, pre-paid users may have an insufficient balance for relatively expensive roaming calls, and there is no contract that allows the operator to collect bills afterwards. Hence, there was a need to develop a more real-time system, so the visited network-and home network-could be sure that the pre-paid balance was sufficient to pay for the consumed services, and that balance would be charged in real time. Whereas operators initially started with different, patchy solutions, a new system was later developed, known as CAMEL. It is a harmonized system, but argued to be expensive to implement [29]. Furthermore, the billing system must be able to deal with double taxation. Finally, fraud can be a bigger issue in roaming than in home markets. In Latin America, fraud causes $5 \%$ of the losses of total mobile revenue, while for roaming this can be up to $25 \%$ [29].

The most recent development in mobile roaming within the E.U. relates to the heterogeneity of national telecommunications markets, which have already been established due to the long history of telecommunications [30]. In the past, consumers had to pay high roaming fees, resulting in reluctant use of roaming. The E.U., who sees roaming as key in building single E.U. market [31], has decided to eliminate roaming tariffs step-by-step [32]. The E.U. approach to roaming is the Roam Like At Home (RLAH) approach, as opposed to the Roam Like A Local (RLAL) approach. This means that the user pays the same tariffs as at their domestic country, as opposed to paying local tariffs. 


\subsubsection{Roaming in the Internet}

The Internet is a network of networks based on the Transmission Control Protocol/Internet Protocol (TCP/IP) suite [33]. Data is transmitted in packets with a technique called packet switching. When data is sent from one computer to the next, the data is cut into data packets, of which multiple are sent independently towards its destination. The two key benefits of packet switching as opposed to circuit switching are (1) efficient use of the network, since one connection can be used for multiple data transmissions, and (2) no dependence on one link, since packets can be routed via another connection if a link stops working. The IP protocol provides for the addressing and forwarding of individual packets.

Internet Service Providers (ISPs) build physical networks in response to market forces [34] and are connected at Internet Exchange Points (IXPs). ISPs can be categorized as Tier 1 ISPs (forming the backbone network, being able to offer connection with the complete Internet), Tier 2 ISPs (regional networks), and Tier 3 ISPs (access networks) [35]. Roaming in the Internet is mainly of interest to Internet Service Providers (ISPs) that want to combine their efforts to achieve a greater service area. Networks are connected either for a fee or without a fee (peering; note that this is a different use of the word peer than in the term peer-to-peer for e-roaming, where it means that parties form a direct connection instead of via a hub). Networks peer with each other because of (perceived) mutual benefits. Tier 1 ISPs peer with other Tier 1 ISPs, while Tier 2 ISPs pay a fee to connect to their network. Tier 2 ISPs peer with other Tier 2 ISPs, while Tier 3 ISPs pay a fee to connect to their network. Tier 3 ISPs provide consumers and content providers access to the Internet, and sometimes also connect with other Tier 3 networks.

In 1991, the Internet Society (ISOC) was established as the main organization responsible for developing technological standards of the internet [36]. There are six groups operating under the ISOC, among which the Internet Engineering Taskforce (IEFT), which is responsible for management of the TCP/IP protocol suite. The groups have a large degree of independence and have relations with both the ISOC and amongst each other. IP address allocation and the Domain Name System (DNS) are handled by the Internet Corporation for Assigned Names and Numbers (ICANN).

A distinctive feature of the management of the Internet is its low level of hierarchy compared to telecommunications. This is reflected in the values explicitly expressed by the Internet Engineering Taskforce (IETF), such as seeing individual contributors as "individuals" rather than representatives of firms or organizations [37] and the end-to-end architectural design principle, meaning that the most important computing tasks take place at the "end" (e.g., a personal computer (PC)) and not in the middle of the network [38]. The end-to-end principle played a role both as a design principle and a governance norm, increasing the chance for network extensions and innovations to arise from actors who do not play a central role in the Internet ecosystem [11,14]. The TCP/IP protocol suite had demonstrated that it was modular, enabling internet administrators, programmers, and users to build and use their own applications and to innovate in many different ways, without needing to change the core of the Internet. This led to a virtuous cycle of a growing number of users, with a growing variety of economic backgrounds, and growing functionality of the network [14].

\subsection{Lessons for E-Roaming}

In the previous subsections, we have described historical standardization processes with the aim of articulating some lessons that can be applied to e-roaming. We have seen that many factors besides technological superiority are related to winning a standards battle. If a single standard does not emerge from such a battle, gateway technologies can become attractive, though these are often sub-optimal from a technical or cost perspective. In its effort to further strengthen the Single Market, the E.U. stimulates the harmonization of standards. Multiple types of EV charging plugs were popular within Europe, and at some point the E.U. decided on one standard to reduce the variety in charging plugs. While there is no serious standardization effort for payment and billing systems in the context of e-roaming, it is a potential scenario for the E.U. to step in when 
interoperability of these systems is not achieved in the coming years. The developments and lessons learned in roaming in telecommunications, when transferred to the e-mobility sector, underline the need for interoperability between market parties, such as charge point operators and mobility service providers, without additional (financial) barriers. Furthermore, issues such as fraud, double taxation, and subscription systems should have priority in protocol design. The success of the Internet underlines the importance of an open management culture and peer-to-peer connectivity. Keeping these lessons in mind, the rest of the paper describes the current state of e-roaming and how to move forward towards a single standard.

\section{EV Charging Infrastructure and E-Roaming}

\subsection{Current Market Situation versus Future Market Situation}

With the rise of electric vehicles, a charging infrastructure has developed. Electric vehicles can be charged at home, at public charging stations, charging stations at office buildings, and semi-public charging stations (for instance, in parking garages or shopping centers) [39]. The field of e-mobility is relatively new, and business models are still developing. Factors that differ between current business models are, for instance, charging power (defining how long a car will occupy a charging station), accessibility of the charge point, and charging fees (a flat fee versus pay per charge) [40]. Furthermore, new trends in mobility and energy give rise to other proposals for future business models, such as car sharing, intermodal transport, vehicle-to-grid technology, battery swapping, and e-roaming [41].

Electric mobility can be seen as a complex system, with multiple actors involved and interrelated, including charge point operators, e-mobility service providers, and roaming hubs [40,42]. Building an efficient and user-friendly charging infrastructure requires them all to communicate. Envisioned future developments will require communication between even more parties. For example, in visions on e-mobility with smart charging, actors from the mobility sector are interacting with actors from the energy sector, such as grid operators, energy producers, and aggregators [43-46]. Including charge points in navigation apps requires information on location, availability, and the tariffs of charging transactions. Finally, transnational e-roaming will require actors from different countries to communicate with each other. Protocols are key in ensuring efficient communication between all parties involved. Protocols both enable and limit the information that parties can share amongst each other, which parties can communicate with each other, and can both enable and hinder certain business models. We illustrate this by showing the current situation of e-roaming in Figures 1 and 2.

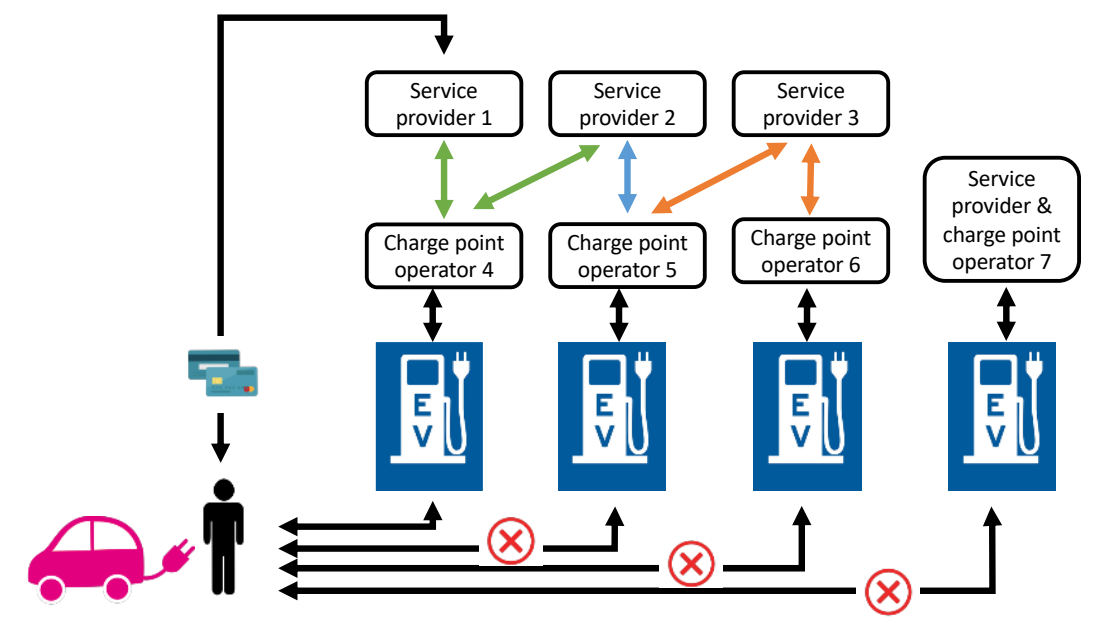

Figure 1. Current market situation, Scenario 1. Peer-to-peer only. Different colours indicate different protocols, and the red arrows show when a user cannot charge at stations of that specific charge point operator. EV, electric vehicle. 


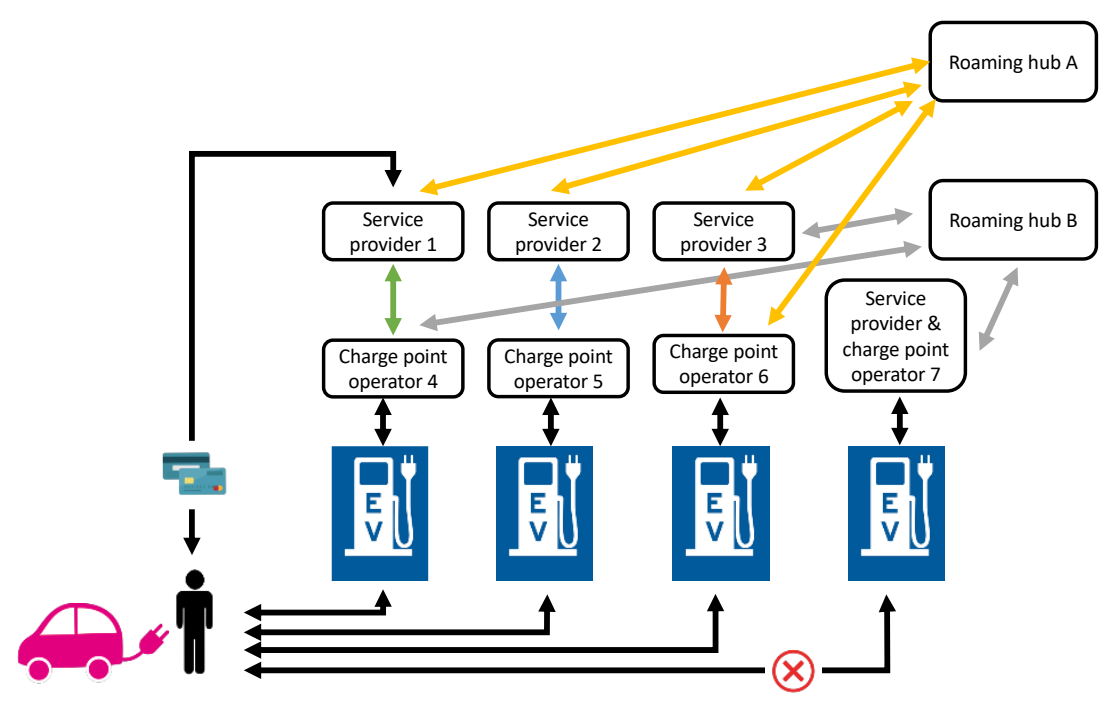

Figure 2. Current market situation, Scenario 2. A combination of peer-to-peer and roaming; two roaming hubs. Different colours indicate different protocols, and the red arrows show when a user cannot charge at stations of that specific charge point operator.

In Figure 1, we show a scenario in which the EV driver has a subscription with service provider 1, and hence can also charge only at stations of charge point operator 4 . To provide a more valuable offer, service providers and charge point operators may want to have more connections, but then need to implement multiple protocols, increasing costs. Figure 2 depicts a situation with two roaming hubs. Thanks to the use of roaming hub A, the EV driver can now also charge at stations of charge point operator 5 and 6 , but not at those of charge point operator 7 (who is only connected to roaming hub B). To provide a more valuable offer, service providers and charge point operators may want to have connections to multiple roaming hubs. However, as each hub is using its own protocol, they need to implement multiple protocols, and pay multiple hub subscription/membership fees, both increasing costs. Switching to another hub requires migration to the protocol that is used by that hub.

We envision a future situation in which only one protocol is needed for connecting both charge point operators and service providers peer-to-peer (decentral) as well as via a roaming hub (central) (Figures 3 and 4).

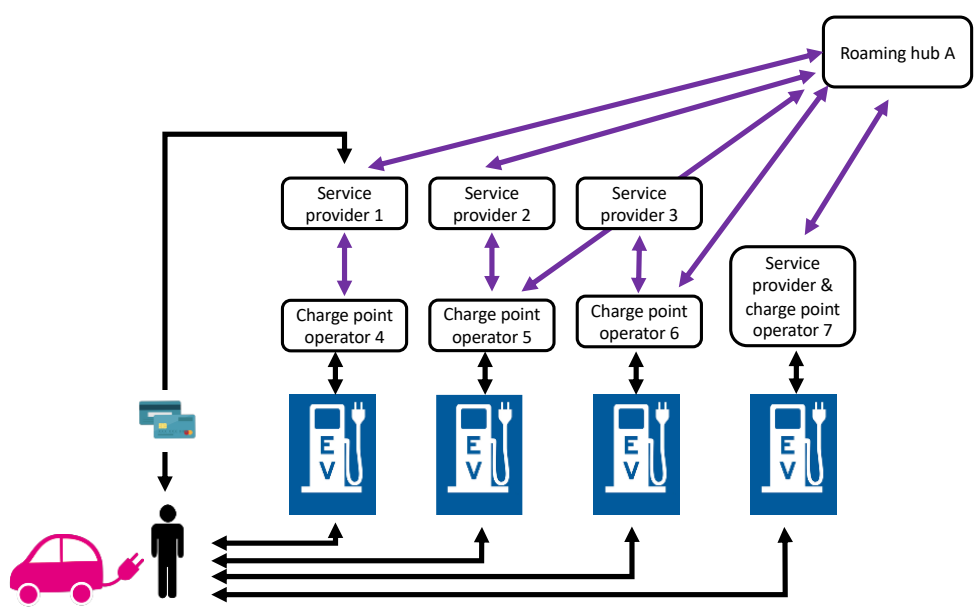

Figure 3. Future market situation, Scenario 3. A combination of peer-to-peer and roaming; one roaming hub. Only a single protocol is used. 


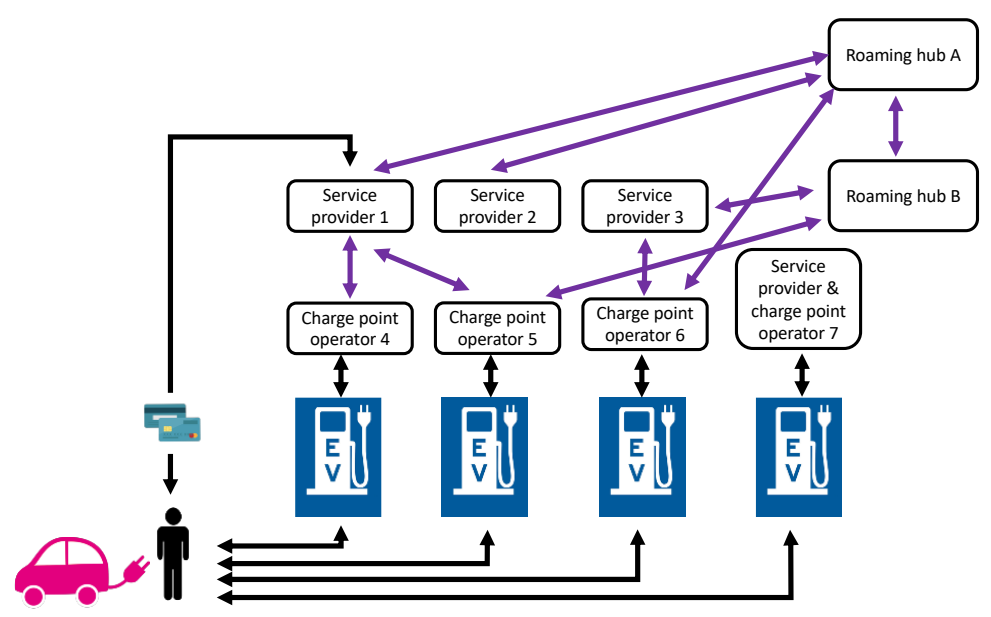

Figure 4. Future market situation, Scenario 4. A combination of peer-to-peer and roaming; two roaming hubs. Only a single protocol is used.

In Figure 3, we depict such a situation with a single roaming hub. Now, the EV driver in the picture can charge at all stations. All parties use the same protocol, reducing the need for duplicate costs. However, the single hub is not subject to competition, and may display monopolistic behavior. Finally, in Figure 4, we show a situation with two roaming hubs. Again, the EV driver can charge at all stations. The two hubs they communicate with each other using the same protocol as all other actors. Thus, all parties use the same protocol, reducing the need for duplicate costs, and there is no monopolist. This will also result in a more level playing field with more competition and lower cost: instead of competition on protocols, the focus will move to competing on services for the EV driver.

\subsection{Rationale for E-Roaming}

Currently, multiple roaming hubs for electric mobility exist in Europe; some more mature than others depending on the maturity of e-mobility in a country. All roaming hubs have developed their own proprietary protocols with varying levels of openness, e.g., members can propose new functionalities. It is difficult to realize roaming between hubs and between charge point operators and service providers who are not connected to a roaming hub. Therefore, an independent and broadly accepted protocol needs to be defined, developed, and implemented that can connect to hubs as well as be used for peer-to-peer connections. In the world of electric mobility, a single protocol to connect both charge point operators and service providers via hubs and peer-to-peer has not yet been developed.

\subsubsection{E.U. Impact}

The electrification of transport has positive effects on energy efficiency and, therefore, on climate ambitions. The urgency is illustrated by the high ambitions for EV deployment and the hard targets to reduce $\mathrm{CO}_{2}$ levels [22]. In terms of legislation and compliancy, our proposed protocol anticipates on increasingly stricter regulation towards the use of open protocols as the default way-of-working, and stricter regulation of the mobility and energy sector. It is compliant with, and supports, developments such as the E.U. Directive on Intelligent Transport Systems [47] (e.g., providing for the location of charging points, the conditions for their use, and the availability through obliged National Access Points) and the Alternative Fuel Directive [4] (e.g., prices for charging sessions should be easy to check and compare, a possibility to charge and pay "ad hoc"—without a contract-should be possible).

\subsubsection{User Impact}

The service for EV drivers will increase in a lot of ways: easy locating of chargers, easy access with one card, app, or similar authentication device, one map of available charging points, transparent and understandable prices, etc. Drivers are able to charge cross-border, at every operator, and using 
the services they know and are familiar with. It will increase and ease e-mobility use, enhance comfort and travelling range, and reduce charging costs. It can also facilitate developments such as direct payment at chargers.

\subsubsection{Products and Services Impact}

By moving towards further harmonization of standards, we move away from country-specific solutions and will create one European playground with improved connectivity between all players. It will serve as a common platform for a whole new ecosystem of new service providers and apps, which will have a positive impact on future employment in this sector. It is also a fertile ground for innovation, as new services may even be introduced beyond e-mobility and charging.

\subsubsection{Technology/ICT Impact}

Using open protocols reduces the cost of access for market parties to enter the market and develop new services. The focus on protocol harmonization acknowledges today's diverse landscape of protocols, which shows the innovative capability of the market. At the same time, it addresses the necessity to converge towards a fully interoperable future with the advantages of scalability and customer focus. E-mobility will be promoted by offering e-mobility infrastructure access in a uniform manner throughout the E.U.

\section{Roaming Initiatives in Europe}

\subsection{Overview Roaming Platforms and Protocols}

Currently, multiple roaming hubs for electric mobility exist in Europe. Some of these are more mature than others, often depending on the state of e-mobility in a country. All roaming hubs have developed their own protocols. Looking at past efforts, it has been proven to be difficult to implement communication interfaces between hubs and between charge point operators and service providers who are not connected to the same roaming hub.

Table 1 presents the roaming protocols that are currently active in Europe. As shown, most protocols support one roaming hub (i.e., a central platform), but have no connection to other roaming hubs. Only one protocol supports peer-to-peer communications (i.e., decentral, without interface with a roaming hub).

Table 1. The roaming protocols in Europe.

\begin{tabular}{cccc}
\hline Protocol & Proprietary/Independent & $\begin{array}{c}\text { Supports Roaming } \\
\text { Hubs }\end{array}$ & $\begin{array}{c}\text { Supports Peer-to-Peer } \\
\text { Connection/Decentral }\end{array}$ \\
\hline Open Clearing House Protocol (OCHP) & Proprietary (e-Clearing.net) & YES & YES \\
Open InterCharge Protocol (OICP) & Proprietary (Hubject) & YES & NO \\
eMobility Inter-Operation Protocol (eMIP) & Proprietary (Gireve) & YES & NO \\
Open Charge Point Interface Protocol (OCPI) & Independent & YES & YES \\
\hline
\end{tabular}

In essence, all roaming protocols have the same goal: to offer roaming to EV drivers across Europe. However, the hubs that use their own proprietary protocol do not communicate with each other and do not exchange data. A service provider or charge point operator who wants to achieve maximum roaming will need to reach an agreement with all major hubs. OCPI can change this. In an ideal situation, the different protocols should be united and converged into one independent and open protocol that can connect both via hubs as well as peer-to-peer. This will reduce the need to connect to every hub, as OCPI offers alternative ways to connect (e.g., peer-to-peer).

\subsection{E-Roaming in The Netherlands with an International Connection}

In the Netherlands, e-roaming in its basic form-allowing EV drivers to charge at every charging station-has been possible since 2011. In that year, the Central Interoperability Register (CIR) was 
established, containing all cards/tokens for public charge stations issued by all service providers active in the Netherlands. This register, created with support of the Dutch government, was transferred to eViolin in 2012. eViolin is an entity that brings together all stakeholders, and managed the CIR register until March 2018. By then, the register supported roaming for over 210,000 EV cards/tokens, 90,000 charge stations, and 22 national charge point operators and mobility service providers. In March 2018, the role of the register was taken over by roaming services. eViolin still plays a key role for these roaming services: among other things, it is responsible for the issuing of IDs of charge point operators and mobility service providers (as of today, there are 26 members, including international ones).

Roaming and information sharing is implemented using the Open Charge Point Information (OCPI) protocol. As discussed above, this protocol supports both peer-to-peer connections and roaming hubs, and, as a result, charge point operators and mobility service providers; navigation service providers are also free to choose their preferred mode of connection. Currently, one roaming hub participates in the initiative: e-clearing.net from Germany. So, charge point operators and mobility providers must connect either directly (peer-to-peer) or via this roaming hub. However, OCPI also supports communication in-between roaming hubs. This way, charge point operators (and mobility providers) could exchange data, even when they are connected to different roaming hubs and when they do not have a direct peer-to-peer connection. Once several roaming hubs adopt OCPI for their in-between connection, more roaming hubs can join the initiative, and then charge point operators and mobility providers can relatively easily switch to another roaming hub. OCPI not only supports roaming, but also functionalities such as remote start/stop, reservations, and the exchange of information on charging tariffs and the location and availability of charge stations. Future versions will support smart charging, ISO 15118 vehicle-to-grid communication, data collection functions, and functionalities relevant to other market roles.

In 2017, the Open Fast Charging Alliance, a group of fast charging operators led by Fastned from the Netherlands, agreed to join the above roaming initiative and to implement OCPI, enabling interoperability of fast chargers across Europe for all involved service providers. This is a change from the previous situation, where fast charging networks were closed systems, and fast chargers could only be used with proprietary apps and tokens.

The Netherlands Knowledge Platform for Public Charging Infrastructure (NKL) is an independent, not-for-profit organization who took up the further development of OCPI. It has recently appointed an OCPI Management Board to ensure further growth and assure continuity (See https://www. nklnederland.com/news/introduction-ocpi-management-board/).

\section{Discussion and Future Work}

We have demonstrated the need for a well-functioning e-roaming system in the E.U., as this is expected to increase EV adoption and can enable new business models for EV charging infrastructure. Though several roaming initiatives do exist, there is no European standard yet. Lessons learned from roaming in telecom and the Internet protocol can be applied to e-roaming, and show OCPI to be an attractive protocol to be further developed.

OCPI is already prototyped, and first implementations are currently taking place, showing a commitment by the market to support and invest in this protocol. The Current Technology Readiness Level (TRL) is estimated to be $6 / 7$. In a new project, we set up a corridor with several adjoining countries (Austria, Germany, Denmark, and the Netherlands) to demonstrate the impact of the protocol (Project website: https://www.evroaming4.eu/). The protocol will interface with existing hubs, such as e-clearing.net, which is an already-proven roaming hub serving multiple European countries. During the project, important new functionalities will be added, collected via consulting a large group of key users in Europe. Finally, a maintenance organization will be set up that gives the protocol the needed level to scale up to a largely adopted protocol. Therefore, during the project, the development of the protocol will shift to TRL 8 and finally reach TRL 9 (system ready for full-scale deployment) as 
the project objectives support the commercial deployment across Europe of numerous business models that rely on standardized information exchange.

Currently, several protocols are being used or developed to support roaming. Developments in other sectors have learned that, over time, these will converge to a single roaming standard. Therefore, it is proposed to start working on a theoretical framework in order to make a comparative analysis between the different protocols and provide recommendations for harmonization and future convergence. Research will be done on how the different existing proprietary protocols can be further harmonized: recognizing their current existence and value, but at the same time providing a roadmap towards a converging future, based on an optimal business ecosystem. This requires different ways of working with and thinking about the existing roaming hubs.

The above illustrates the ambition of developing OCPI in terms of interoperability, solutions, ICT, and collaboration, and its potential to support the breakthrough and widespread uptake of electric mobility.

Author Contributions: Conceptualization, investigation, writing (original draft preparation), visualization, and funding acquisition: R.F. and M.B. Investigation and writing (review and editing): M.v.d.K. and R.B.

Funding: This research was funded by Electric Mobility Europe under the project evRoaming4EU, grant number EME-31.

Acknowledgments: The authors would like to thank the two anonymous reviewers, whose comments helped us improve our manuscript.

Conflicts of Interest: R.F. and M.B. are involved in the development, management, and promotion of OCPI through the foundation NKL. M.v.d.K. and R.B. declare no conflict of interest. The funders had no role in the design of the study; in the collection, analyses, or interpretation of data; in the writing of the manuscript, or in the decision to publish the results.

\section{References}

1. ACEA. New Passenger Car Registrations by Alternative Fuel Type in the European Union. 2018. Available online: https://www.acea.be/statistics/tag/category/electric-and-alternative-vehicleregistrations (accessed on 26 November 2018).

2. Nikitas, A.; Kougias, I.; Alyavina, E.; Njoya Tchouamou, E. How Can Autonomous and Connected Vehicles, Electromobility, BRT, Hyperloop, Shared Use Mobility and Mobility-As-A-Service Shape Transport Futures for the Context of Smart Cities? Urban Sci. 2017, 1, 36. [CrossRef]

3. Malmgren, I. Quantifying the societal benefits of electric vehicles. World Electr. Veh. J. 2016, 8, 996-1007. [CrossRef]

4. European Commission. Directive 2014/94/EU of the European Parliament and of the Council of 22 October 2014 on the Deployment of Alternative Fuels Infrastructure. 2014. Available online: https:/ / eur-lex.europa. eu/legal-content/en/TXT/?uri=CELEX\%3A32014L0094 (accessed on 26 November 2018).

5. Adam, M. Accelerating E-Mobility in Germany: A Case for Regulations; SpringerBriefs in Law: Cham, Switzerland, 2016.

6. Navigant Research. Electric Vehicle Charging Services. 2016. Available online: https://www. navigantresearch.com/reports/electric-vehicle-charging-services (accessed on 14 June 2018).

7. Krechmer, K. Technical standards: Foundations of the future. StandardView 1996, 4, 4-8. [CrossRef]

8. David, P.A.; Greenstein, S. The economics of compatibility standards: An introduction to recent research. Econ. Innov. New Technol. 1990, 1, 3-41. [CrossRef]

9. David, P.A.; Steinmueller, W.E. Economics of compatibility standards and competition in telecommunication networks. Inf. Econ. Policy 1994, 6, 217-241. [CrossRef]

10. Blind, K. Standardisation: A Catalyst for Innovation; Inaugural Addresses Research in Management Series; Erasmus University Rotterdam: Rotterdam, The Netherlands, 2009; ISBN 978-90-5892-220-5.

11. De Nardis, L. Protocol Politics: The Globalization of Internet Governance; MIT Press: Cambridge, MA, USA, 2009; ISBN 978-0-262-04257-4.

12. Townes, M. The spread of TCP/IP: How the internet became the internet. Millennium 2012, 41, 43-64. [CrossRef] 
13. Van de Kaa, G.; Van den Ende, J.; De Vries, H.J.; Van Heck, E. Factors for winning interface format battles: A review and synthesis of the literature. Technol. Forecast. Soc. Chang. 2011, 78, 1397-1411. [CrossRef]

14. Greenstein, S. How The Internet Became Commercial: Innovation, Privatization, and the Birth of a New Network; Princeton University Press: Princeton, NJ, USA, 2015; ISBN 978-0-691-16736-7.

15. Bekkers, R.; Verspagen, B.; Smits, J. Intellectual property rights and standardization: The case of GSM. Telecommun. Policy 2002, 26, 171-188. [CrossRef]

16. Simcoe, T. Open standards and intellectual property rights. In Open Innovation: Researching a New Paradigm; Chesbrough, H., Vanhaverbeke, W., West, J., Eds.; Oxford University Press: Oxford, UK, 2006; pp. 161-183.

17. Kang, B.; Bekkers, R. Just-in-time patents and the development of standards. Res. Policy 2015, 44, $1948-1961$. [CrossRef]

18. World Trade Organization Committee on Technical Barriers to Trade. Second Triennial Review of the Operation and Implementation of the Agreement on Technical Barriers to Trade. Document G/TBT/9. 2000. Available online: https:/ / docsonline.wto.org/dol2fe/Pages/SS/DirectDoc.aspx?filename=t $\% 3 \mathrm{~A} \% 2 \mathrm{Fg} \%$ 2Ftbt\%2F9.doc\& (accessed on 26 November 2018).

19. European Commission. Communication COM(2010) 245 Final/2 from the Commission to the European Parliament, the Council, the European Economic and Social Committee and the Committee of the Regions: A Digital Agenda for Europe. Brussels. 2010. Available online: http:/ / ec.europa.eu/transparency/regdoc/ rep/1/2010/EN/1-2010-245-EN-F2-1.Pdf (accessed on 26 November 2018).

20. Bøgh, S.A. A World Built on Standards-A Textbook for Higher Education; Danish Standards Foundation: Nordhavn, Denmark, 2015; ISBN 978-87-7310-964-9.

21. European Union. Directive 98/34/Ec of the European Parliament and of the CouncIL. 1998. Available online: https:/ / eur-lex.europa.eu/legal-content/EN/ALL/?uri=CELEX\%3A31998L0034 (accessed on 26 November 2018).

22. European Commission. The Paris Protocol-A Blueprint for Tackling Global Climate Change Beyond 2020. 2015. Available online: https:/ / eur-lex.europa.eu/legal-content/EN/ALL/?uri=CELEX\%3A31998L0034 (accessed on 26 November 2018).

23. Spöttle, M.; Jörling, K.; Schimmel, M.; Staats, M.; Grizzel, L.; Jerram, L.; Drier, W.; Gartner, J.; Thomas, M.; Ratcliff, C.; et al. Research for TRAN Committee-Charging Infrastructure for Electric Road Vehicles, European Parliament. Brussels. 2018. Available online: http:/ / www.europarl.europa.eu/RegData/etudes/ STUD/2018/617470/IPOL_STU(2018)617470_EN.pdf (accessed on 26 November 2018).

24. Gerst, M.; Xudong, G. Electric Vehicle Standards in Europe and China-A Snapshot of the Current Situation. PIK-Prax der Informationsverarbeitung und Kommun 2014, 37, 225-231. [CrossRef]

25. Bakker, S.; Leguijt, P.; Van Lente, H. Niche accumulation and standardization-The case of electric vehicle recharging plugs. J. Clean. Prod. 2015, 94, 155-164. [CrossRef]

26. Van der Bossche, P. The Electric Vehicle: Raising the Standards. Ph.D. Thesis, Vrije Universiteit Brussel, Brussel, Belgium, April 2003.

27. Wiegmann, P.M.; In, K.; Jakobs, H.J.; de Vries, A.; Ganesh, A.G.I. Combining Modes of Standard Setting-Analysing Strategies and the Case of Connectors for Charging Electric Vehicles in Europe. In Proceedings of the EURAS proceedings 2013-Standards: Boosting European competitiveness, Brussels, Belgium, 24-26 June 2013; pp. 397-411.

28. ElaadNL. EV Related Protocol Study v1.1. 2017. Available online: https://www.elaad.nl/research/evrelated-protocol-study/ (accessed on 26 November 2018).

29. GSMA. International Roaming Explained. 2012. Available online: https://www.gsma.com/ publicpolicy/wp-content/uploads/2012/09/Africa-International-roaming-explained-English.pdf (accessed on 26 November 2018).

30. Spruytte, J.; Van der Wee, M.; de Regt, M.; Verbrugge, S.; Colle, D. International roaming in the EU: Current overview, challenges, opportunities and solutions. Telecommun. Policy 2017, 41, 717-730. [CrossRef]

31. Infante, J.; Vallejo, I. Regulation of international roaming in the European Union-Lessons learned. Telecommun. Policy 2012, 36, 736-748. [CrossRef]

32. European Commission. Commission Implementing Regulation (EU) 2016/2286. 2016. Available online: https: / / eur-lex.europa.eu/legal-content/EN/TXT/?uri=CELEX\%3A32016R2286 (accessed on 26 November 2018). 
33. Cave, M.; Mason, R. The economics and regulation of the Internet. Oxf. Rev. Econ. Policy 2001, 17, 118-201. [CrossRef]

34. Simonelis, A. A Concise Guide to the Major Internet Bodies. Ubiquity. 2005. Available online: https: / / ubiquity.acm.org/article.cfm?id=1071915 (accessed on 26 November 2018).

35. Gill, P.; Arlitt, M.; Li, Z.; Mahanti, A. The Flattening Internet Topology: Natural Evolution, Unsightly Barnacles or Contrived Collapse? In International Conference on Passive and Active Network Measurement; Springer: New York, NY, USA, 2008; pp. 1-10.

36. The Internet Society. Internet Ecosystem: Naming and Addressing Shared Global Services and Operations, and Open Standards Development. 2014. Available online: https:/ /www.internetsociety.org/resources / doc/2014/internet-ecosystem/ (accessed on 26 November 2018).

37. DeNardis, L.; Tam, E. Open documents and democracy: A Political Basis for Open Document Standards. SSRN 2007. [CrossRef]

38. Saltzer, J.H.; Reed, D.P.; Clark, D.D. End-to-end arguments in system design. ACM Trans. Comput. Syst. 1984, 2, 277-288. [CrossRef]

39. Martínez-Lao, J.; Montoya, F.G.; Montoya, M.G.; Manzano-Agugliaro, F. Electric vehicles in Spain: An overview of charging systems. Renew. Sustain. Energy Rev. 2017, 77, 970-983. [CrossRef]

40. Madina, C.; Zamora, I.; Zabala, E. Methodology for assessing electric vehicle charging infrastructure business models. Energy Policy 2016, 8, 284-293. [CrossRef]

41. Laurischkat, K.; Viertelhausen, A.; Jandt, D. Business Models for Electric Mobility. Procedia CIRP 2016, 47, 483-488. [CrossRef]

42. Fanti, M.P.; Pedroncelli, G.; Roccotelli, M.; Mininel, S.; Stecco, G.; Ukovich, W. Actors interactions and needs in the European electromobility network. In Proceedings of the 2017 International Conference on Service Operations and Logistics, and Informatics, Bari, Italy, 18-20 September 2017; pp. 162-167. [CrossRef]

43. Rubino, L.; Capasso, C.; Veneri, O. Review on plug-in electric vehicle charging architectures integrated with distributed energy sources for sustainable mobility. Appl. Energy 2017, 207, 438-464. [CrossRef]

44. Mwasilu, F.; Justo, J.J.; Kim, E.K.; Do, T.D.; Jung, J.W. Electric vehicles and smart grid interaction: A review on vehicle to grid and renewable energy sources integration. Renew. Sustain. Energy Rev. 2014, 34, 501-516. [CrossRef]

45. Mustafa, M.A.; Zhang, N.; Kalogridis, G.; Fan, Z. Roaming electric vehicle charging and billing: An anonymous multi-user protocol. SmartGridComm 2014, 2015, 939-945. [CrossRef]

46. García-Villalobos, J.; Zamora, I.; San Martín, J.I.; Asensio, F.J.; Aperribay, V. Plug-in electric vehicles in electric distribution networks: A review of smart charging approaches. Renew. Sustain. Energy Rev. 2014, 38, 717-731. [CrossRef]

47. European Commission. A European Strategy on Cooperative Intelligent Transport Systems, a Milestone Towards Cooperative, Connected and Automated Mobility. 2016. Available online: https:/ / ec.europa.eu/ energy/sites/ener/files/documents/1_en_act_part1_v5.pdf (accessed on 26 November 2018).

(C) 2018 by the authors. Licensee MDPI, Basel, Switzerland. This article is an open access article distributed under the terms and conditions of the Creative Commons Attribution (CC BY) license (http://creativecommons.org/licenses/by/4.0/). 